Article

\title{
Organizational Adoption of Social Media in the Hospitality Industry: An Integrated Approach Based on DIT and TOE Frameworks
}

\author{
Adamantia Pateli ${ }^{1}$, Naoum Mylonas ${ }^{2, *(\mathbb{D})}$ and Aggeliki Spyrou ${ }^{1}$ \\ 1 Department of Informatics, Ionian University, Tsirigoti Square 7, 49100 Corfu, Greece; pateli@ionio.gr (A.P.); \\ c15spyr@ionio.gr (A.S.) \\ 2 Department of Tourism, Ionian University, P. Vraila Armeni 4, 49132 Corfu, Greece \\ * Correspondence: nmylonas@ionio.gr or naoumyl@hotmail.com
}

Received: 28 July 2020; Accepted: 28 August 2020; Published: 1 September 2020

\begin{abstract}
The importance of the organizational adoption of social media is increasingly raised in hospitality literature because of the recognition of Web 2.0 technologies as a significant tool for improving customer information searching and experience, as well as for enriching firm digital strategy. The present study seeks to empirically explore the determinant factors that affect a hospitality firm's decision to adopt social media by following a theoretical approach that integrates the Diffusion of Innovation Theory (DIT) with the Technology-Organization-Environment (TOE) framework. Using survey data from 106 hospitality firms operating in Greece, and by applying structural equation modelling (SEM), we identify seven factors that influence the adoption of organizational social media adoption. These factors are grouped into three categories: Technological, organizational, and environmental. Out of the three groups of factors, technological features are considered as the most important ones in terms of their predicting power. Theoretical and practical implications of our findings are discussed.
\end{abstract}

Keywords: social media adoption; diffusion of innovation theory; TOE; hospitality industry

\section{Introduction}

Tourism industry has been recognized, since the decade of 2000, as one of the fastest growing industries in the world in terms of online transactions [1,2]. Many tourist businesses, such as hotels, restaurants, and travel agencies, have been greatly favored by the internet's growth. The organizational adoption of Web 2.0 technologies, such as blogs, social networks, internet forums, calendars, wikis, podcasts, messaging applications, file sharing services, and tagging, enhances firms' need to increase connection and collaboration with their market [3,4]. Social media refers to interactive Web 2.0 services that enable users to contribute to developing, rating, collaborating, and distributing internet content and customizing internet applications [5]. The latest dynamics of the Web 2.0 technologies have led to a rise of an interactive internet, the value of which primarily derives from the contributions of its users. An example of this interactive internet is the expansion of user-generated content (UGC) and social media platforms $[1,6]$.

Traditionally, tourism firms have been, for quite a few years, reluctant to adopt Information Technology (IT) innovations and to follow the industry shift towards technology-driven management $[7,8]$. The adoption of social media by the hospitality industry firms was rather low during the first years of Web 2.0 technologies' expansion [9]. This was mainly due to the high levels of expected risk. Nevertheless, such fears seem to gradually grow faint and disappear, as during the last decade many tourism firms have acknowledged the necessity of using Web 2.0 technologies and especially social media 
not only for achieving reduction of operational costs, but also for improving their customer relationships, hence building their brand loyalty within the community $[8,10]$, and increasing their product/service innovativeness [11,12]. In parallel, an increasing number of tourists use social media throughout the planning as well as the execution stage of the travel experience (i.e., for finding their hotel, for booking it, for reading review comments and uploading their opinion for other peers).

Social media has become an integral part of most firms' marketing strategy. Web 2.0 applications have significantly changed how tourism firms, such as hotels and airlines, create value for their customers by providing them with online access to information regarding reservation as well as evaluation of their tourist products/services [13]. TripAdvisor is considered an essential part in any hospitality business' social media strategy. As many hoteliers know, it is a huge source of market information and a valuable communication channel with their potential guests. According to Travolution research, $40 \%$ of millennial travelers (aged 18-33) make their hospitality choice based on how 'Instagrammable' a hotel or accommodation is. These results prove how important it is for hospitality firms to showcase their property through their social media, and thus benefit from the electronic word of mouth effects. Moreover, social media has enhanced the possibilities for value capture by enabling them to improve communication and interaction with their customers during their trip [9,14]. In 2018, Amazon released 'Alexa for Hospitality', a virtual concierge which can assist guests during their stay by ordering towels, checking out, ordering room service, or asking for advice on what to do in the local area. In this respect, social media platforms are considered as a strategic tool used not only for marketing, but also for innovation development in the hospitality industry $[15,16]$.

The research interest on social media in the tourism industry is not new and has been explored in several studies and within various contexts $[4,7,17,18]$. Specifically, within the previous decade, there was a great bulk of research studies investigating the motives as well as the value gained through social media by candidate or actual visitors $[19,20]$. Apart from the demand side, another set of research studies have investigated the supply side of social media in the tourism industry. Dealing with the ever-increasing external pressure and environment uncertainty, sourced from both evolving market demands as well as competition intensity, hospitality firms have no other option but to combine the use of traditional marketing tools with social media to increase their visibility, but also their service attractiveness, to potential customers. A great number of articles have already highlighted the significance and implications of social media adoption in the hospitality industry [21]. The primary research emphasis is on investigating the business goals as well as the performance of tourist professionals and firms having included social media in their marketing strategy $[10,20,22,23]$. However, so far, researchers of the tourism management literature have not resulted in any consolidated and coherent sets of antecedent factors affecting the organizational adoption of social media in the hospitality industry.

This study develops a comprehensive framework of factors affecting hospitality firms' decision to adopt social media, including features of the technology, the organization itself, as well as the environment in which hospitality firms operate. The significance of this survey also rests on providing a composite variable which can measure social media adoption, integrating the aspect of both time and usage intensity, a critical parameter for deciding on a hospitality firm's social media profile. To achieve our research objective, we follow a theoretical approach that integrates the Diffusion of Innovation (DIT) framework [24], one of the most popular and cited theories for investigating and understanding the adoption and implementation of innovations, with the Technology-Organization-Environment (TOE) framework [25], a widely used framework to examine elements that shape a firm's decision to adopt IT. Having identified a number of critical determinant factors from the DIT, we put them forth within the three dimensions of the TOE framework in order to develop three groups of hypotheses on the antecedents of social media's organizational adoption. Moreover, using the DIT principles, we develop the composite construct of social media adoption. By applying Partial Least Squares (PLS) —Structural Equation Modelling (SEM), we test our hypotheses on a dataset of 106 firms operating in the Greek hospitality industry. 


\section{Theoretical Background}

\subsection{Diffusion of Innovation Theory (DIT)}

Different theories have been formulated to examine innovation adoption. DIT is an extensive social and psychological theory that aims to predict how people and organizations make decisions to adopt a new innovation by finding their adoption patterns and understanding its structure [26,27]. Innovation in DIT is defined as an "idea, practice, or object that is perceived as new by an individual or other unit of adoption" (Rogers [28] (p. 7)). Adoption embraces the concept of introduction and implementation [24].

Organizational adoption of innovation refers to "the implementation of an internally generated or a borrowed idea-whether pertaining to a product, device, system, process, policy, program, or service- - that was new to the organization at the time of adoption" (Damanpour and Evan [29] (p. 93)). Organizational adoption is addressed at different levels of the organization, such as functional teams, business units or entire organizations [30]. At an organizational level, innovation adoption can be reflected on the firm's decision to adopt, intention to adopt, intention to use, as well as actually use of a new technology [31].

The organizational DIT research stream consists of three classes of predictors of organizational innovation adoption: (1) Innovation characteristics, (2) organizational characteristics, (3) environmental characteristics. Innovation-technological characteristics may include relative advantages, complexity, compatibility, observability, perceived usefulness, and ease of use [32]. Regarding the organizational characteristics, main predictors of innovation adoption are considered top or middle management support, organization structure - centralization, internal influence, and organization size. Moreover, Jeyaraj et al. [31] illustrate three predictors related to environmental characteristics, namely external pressure, competition intensity, environment uncertainty and sector.

DIT theoretical framework has been used by several studies in the hospitality literature in order to identify factors that affect innovation adoption. Specifically, Hashim et al. [33] have applied DIT in order to investigate the relationships between Malaysian hotel characteristics (size, rating, and affiliation) and internet adoption. The findings disclose that large, high rated, and affiliated hotels had a higher email and website presence, and further, they adopted IT earlier than the small, low rated, and non-affiliated hotels. Le et al. [34] applied the DIT theoretical framework in order to identify factors that influence the intentions of Vietnamese hotel businesses to adopt sustainable tourism practices. Their empirical research indicated that innovation characteristics (i.e., observability, relative advantage) were the most influential factors. External environment characteristics (i.e., perceived competition) followed in significance, while organizational characteristics (i.e., firm size, location, attitude toward change/risk-taking) had a weaker relationship with the adoption. In a similar vein, Smerecnik and Andersen [35] have applied DIT in order to examine the diffusion of IT innovation in North American hotels and ski resorts for environmental sustainability reasons. Results from this study revealed that the certain innovation features, such as perceived simplicity and relative advantage of sustainability innovations, combined with certain organizational characteristics, such as high levels of opinion leadership and innovativeness of hotels/resorts, were most strongly associated with the adoption of sustainability innovations.

Concerning the social media adoption, the DIT theoretical framework was employed by Clarke et al. [36] for conducting an exploratory study on how celebrity chefs (as individuals, but also as organizations) have adopted and implemented social media innovation. The pilot study found a significant country difference in implementation at the individual, but not at the organizational level. However, scholars in general, and in hospitality and tourism specifically, call for additional research on factors related to the organizational implementation of innovations [37]. 


\subsection{The Technology-Organization-Environment (TOE) Framework}

The Technology-Organization-Environment (TOE) theoretical framework was developed by Tornatzky et al. [25] for the assessment of conditions that affect a firm's decision to adopt IT innovations. There is an increasing interest in the literature for the use of TOE framework in order to determine how elements falling under technology, organization, and environment dimensions influence implementation, post-implementation, and performance indicators of IT systems and applications [38-41].

The TOE framework has been applied in several empirical studies that examine factors affecting implementation, use, and performance of IT in the tourism and hospitality industry. Leung et al. [42] conducted an exploratory study aiming to examine the factors affecting information and communication technology initial, but also continued adoption by an independent hotel in Hong Kong using the Technology-Organization-Environment (TOE) framework. Drawing on the content analysis of in-depth interviews with four key informants of the studied hotel, this study empirically demonstrated that the extent of expected benefits brought by Information and Communication Technology (ICT) is a primary criterion determining the studied hotel's decision about whether or not to adopt ICT. In addition, to assessing the expected benefits, the inter-compatibility and potential risk of integrating the technologies was found to be crucial in affecting a hotel's inclination to ICT adoption. From the organization's point of view, financial readiness and technological readiness were found to be the main determinants affecting the studied hotel's adoption of ICT and its continued usage. With regard to the environmental forces, perceived pressure from the industry, trading partners, and customers were well acknowledged and found to have a certain impact on the studied hotel's adoption of ICT and its continued usage. Wang et al. [43] explored why hotels in Taiwan adopt mobile reservation systems based on the technology-organization-environment (TOE) framework. The results indicate that compatibility, firm size, technology competence, and critical mass are significantly positively related to mobile hotel reservation systems adoption, while complexity is significantly negatively related.

TOE has recently been applied for the investigation of social media use by firms of the hospitality sector. Ndekwa and Katunzi [44] surveyed the factors influencing adoption of online social media among small and medium tourist enterprises in Tanzania and their findings revealed that organizational and environmental context are significantly influencing adoption of social media, while technology context was found to be insignificant factor. More recently, Matikiti et al. [45] employed both Technology Acceptance Model (TAM) and TOE framework to identify factors that influence attitude towards the use of social media marketing by small tourism businesses (tour operators, travel agencies) in South Africa. The results showed that out of organizational factors, managerial support and managers' level of education are the main factors which influence attitude towards the use of social media marketing. The environmental context affects social media marketing adoption through the pressure from competitors. Finally, perceived benefits and perceived ease of use were found to be the most prominent technological factors which influence the use of social media marketing. Organization context is the most prominent determinant group of factors, while environment and technology contexts follow in significance of influence. In a similar vein, the study of Barbe and Pennington-Gray (2018) wished to investigate the factors that influence their use of social media for crisis communication. While they have argued for the use of TOE, in essence they have emphasized organizational factors provided by this framework. Their results indicate that more chain hotels than independent hotels used social media for crisis management.

\section{Hypotheses Development and Conceptual Model}

In a synthesis of IT adoption models at the firm level, Oliveira and Martins [46] noted that Diffusion Innovation Theory (DIT) [28] and the TOE framework [25] are robust in explaining technology adoption. Hsu et al. [47] also acknowledged that the TOE framework complements the DIT in better explaining innovation adoption and diffusion. Following this perspective, our article has integrated the DIT within the TOE framework in order to develop a research model that identifies seven prime antecedents 
of social media adoption in the hospitality industry. The first two, 'relative advantage' and 'presence', are sourced from the DIT theory, while the third one, 'interconnections', is sourced from studies applying the TOE framework $[21,31,48]$. The feature of 'top management support' is commonly used by both DIT and TOE [21,31,49], while 'organization innovativeness' is basically sourced from DIT [31,32]. Regarding the last two environmental features, while 'external pressure' is studied by both frameworks [46,49-51], the 'environment uncertainty' construct is explicitly investigated in TOE $[49,52,53]$. Finally, drawing upon the DIT framework, we conceptualized Social Media Adoption (SMA) as a rather composite variable, used to denote not only the usage of social media, but also the diffusion, which is conceptualized as the extent to which organizations exploit social media. The diffusion is operationalized in terms of intensity-number of social media tools used as well as time of adoption - the duration of social media use.

\subsection{Technological Features as Antecedents of Organizational Social Media Adoption}

Social media tools are used extensively throughout tourism industry for experience sharing. Tourism firms that have adopted social media tools experience a comparative advantage in reputation because they affect tourists' final decisions in holiday planning [54]. Social media also gives the ability to the tourism firms to acquire more observability and to develop more interconnections with their peers and their customers [55]. Prior research in tourism and hospitality literature discusses a number of technological features of social media, such as compatibility [34,42,43], relative advantage [34,43], complexity [34,43], and observability [34]. In this study, we have identified the most typical but also innovation-related features of social media that could be considered as important antecedents of their organizational adoption. In particular, we have selected to examine the impact of the features 'relative advantage', 'presence', and 'interconnections', as they have been frequently used in the literature of social media adoption $[41,43,56,57]$. These features have been examined in the relevant research of social media adoption in hospitality [42,43]. We posit in this study the following hypothesis:

Hypothesis 1. (H1): Technological features have a positive influence on SMA by hospitality firms.

'Relative advantage' is encountered extensively in prior research dealing with the adoption and diffusion of innovation $[20,25,58,59]$. Relative advantage is defined as "a degree to which an innovation is perceived as providing more benefits than its predecessor" (Min et al. [26] (p. 772)). Relative advantage encloses the consideration of the return on investment before adopting an innovation [35]. In this vein, the relative advantage addresses the extent to which an innovation is expected to be more beneficial to a business compared to other innovative tools $[58,60]$. Especially in the hospitality industry, social media have been preferred for a variety of reasons, such as the location-based and customized services, the easier information accessibility, the operational cost reductions due to reduced paperwork, and the decrease in response time due to the improved speed of the room reservation process [42]. Accordingly, the following hypothesis is proposed:

Hypothesis 1a. (H1a): The 'relative advantage' feature of social media has a positive influence on SMA by hospitality firms.

'Presence' demonstrates the business's ability to be visible for third parties. It is quite similar to the term 'observability', and reveals the extent to which the effects of an innovation are visible in third parties [61]. Nowadays, social media provides the ability to share knowledge and develop communication channels. They also provide the opportunity to increase the visibility of a company to its market, competitors, and partners through different ways [62]. Social media is an effective marketing channel able to be wisely applied in the integrated marketing of tourism and hospitality services [55]. Equally, hospitality firms can also be in a position to exploit all the advantages that are offered by user-generated content if they have presence in social media [63]. Accordingly, the following hypothesis is proposed: 
Hypothesis 1b. (H1b): The 'presence' feature of social media has a positive influence on SMA by hospitality firms.

'Interconnections' or 'associations' are established connections between individuals or between organizations or between individuals and organizations. Many social media, mostly social networks and social tagging, use algorithms to identify and recommend new associations to users based on their profile as well as their social media behavior (e.g., their search behavior, their likes, etc.) [62,64]. According to Treem and Leonardi [62], the "interconnections" feature of social media can support existing social connection of firms, give them access to relevant information-wherever this comes from-and enable them to develop new connections. Given the transformation of "space" in the hospitality industry through the adoption of social media, these interconnections take place increasingly in virtual platforms of communication [3]. Hospitality firms are more likely to adopt social media when they attribute value to the interconnections feature. Accordingly, the following hypothesis is proposed:

Hypothesis 1c. (H1c): The 'interconnections' feature of social media has a positive influence on SMA by hospitality firms.

\subsection{Organizational Features as Antecedents of Organizational Social Media Adoption}

Organizational features relate with the internal characteristics of the firm, such as its size, centralization or formalization of processes, staffing, and management issues [25]. Regardless of the benefits of IT, it is important to firms to consider whether their resources and capabilities are adequate in order to support the adoption [42,43]. In the hospitality industry, certain studies have found that organizational features influence SMA by creating a favorable organizational environment and by mobilizing the appropriate resources $[41-43,65]$. In line with prior research $[41,57,66]$, top management support has been adopted, and following the directions of Jeyaraj et al. [31], innovativeness has also been adopted to explain the organizational dimension. Hence, we have formulated the following hypothesis:

Hypothesis 2. (H2): Organizational features have a positive influence on SMA by hospitality firms.

'Top management support' includes approval from either the executive board or the middle management team to execute a project, and also enthusiastic support, which is transmitted throughout the organization at all levels [58]. Furthermore, the top or middle management exerts an influence on the availability and the coordination of all resources by ensuring that adequate financial resources, time, and human talent are available for the SMA [67]. Top management can also generate a favorable environment to facilitate SMA by creating an appealing vision of how the adoption will benefit the firm and overcoming any member resistance to the change [43]. In fact, managers that are up-to-date with emerging technology and positively disposed towards social media are in a better position to support the organizational SMA [35]. Based on Leung et al.'s [42] findings about a hotel's SMA, top management's support, vision, and commitment seem to critically enhance the creation of a supportive climate for SMA and provide the strategic directions to achieve it [42]. Thus, hospitality firms with a supportive top management are more likely to adopt social media. Accordingly, the following hypothesis is proposed:

Hypothesis 2a. (H2a): Top management support has a positive influence on SMA by hospitality firms.

A factor that has not yet received enough attention for empirical examination in the literature is 'innovativeness', which is defined as "the degree to which an individual or other unit of adoption is relatively earlier in adopting new ideas than other members of a social system" (Rogers [32] (p. 990)). Hurt et al. [68] described innovativeness as a willingness to change. Innovativeness serves as a key component to firms for both the adoption and diffusion of new technology. Even in the case of scarce resources and business environments characterized by uncertainty, innovativeness plays a critical role to firms in adopting social media, because innovative firms or individuals are considered more prone 
to undertake risks $[32,69]$. In this vein, hospitality firms characterized by innovativeness are in a better position to adopt social media. Accordingly, the following hypothesis is proposed:

Hypothesis 2b. (H2b): Innovativeness has a positive influence on SMA by hospitality firms.

\subsection{Environmental Features as Antecedents of Organizational Social Media Adoption}

Environmental features concern factors that are external to an organization and constitute opportunities and constraints for the adoption of technological innovations [25,42]. The dynamics of business environment in which firms operate have been argued to exert a pressure on them for the adoption of ICT $[42,60]$. Particularly, firms in service industries, like the hospitality industry, that rely on the processing of information, face the challenge of adopting new technologies in order to maintain their competitive position $[42,65,70]$. In this research, we have selected to examine two of the most commonly discussed environmental factors, namely 'external pressure' and 'environment uncertainty', in order to explain the impact of the external environment on social media adoption by firms of the hospitality industry.

Hypothesis 3. (H3): Environmental features have a positive influence on SMA by hospitality firms.

'External pressure' is viewed as one of the most crucial factors of IT adoption including pressure from competitors, peers, governments, trading-partners, and customers [42,43,65,71]. External pressure is conceptualized to incorporate institutional bandwagon pressure and competitive bandwagon pressure [72]. Institutional bandwagon pressure concerns the fear of non-adopters to look abnormal and therefore less legitimate to their peers and stakeholders. Competitive bandwagon pressure is driven by the fear of lost competitive advantage, which urges firms to react and adopt innovation. In addition, firms are often under pressure from partners to maintain their technological status in line with them. The reason beyond this pressure to firms is the rationale to use compatible applications for communicating and exchanging information with their trading partners [41,73]. In their study regarding travel agencies, Wang and Cheung [74] reached the conclusion that external pressure is positively related to SMA [74]. Respectively, the study of Matikiti et al. [45] concluded that external pressure is a strong predictor of SMA in the hospitality industry [45]. Based on these suggestions, our study hypothesizes that hospitality firms are more likely to adopt social media when they believe that non-adoption will lead them to a competitive disadvantage. Accordingly, the following hypothesis is proposed:

Hypothesis 3a. (H3a): External pressure has a positive influence on SMA by hospitality firms.

Business environment can be characterized as dynamic or stable, depending on its uncertainty rates. 'Environment uncertainty' can be conceptualized through three main dimensions: Dynamism, heterogeneity, and hostility $[75,76]$. Firms are often forced to act and respond dynamically to environment uncertainty, driven by a fear of losing market shares from their competitive firms $[77,78]$. Because of environment uncertainty, entrepreneurs and managers tend to act proactively based on well-informed conjectures about the strategic path ahead [79]. Social media operates as a significant avenue through which firms wish to increase their market reach, as well as their innovation performance and competitiveness under conditions of increased competition intensity and market uncertainty $[70,74]$. Thus, competitiveness and dynamism of the environment encourage firms to adopt technological innovations, such as social media, for dealing with environment dynamism and gaining competitive advantage [80]. Based on these directions, our study perceives that hospitality firms experiencing environment uncertainty are more likely to adopt social media because environment uncertainty enables them to act proactively and respond dynamically. Our study supports that hospitality firms are inclined to invest more on social media in order to effectively tackle the competition in an uncertain environment. Accordingly, the following hypothesis is proposed: 
Hypothesis 3b. (H3b): Environment uncertainty has a positive influence on SMA by hospitality firms.

\section{Research Method}

\subsection{Research Design}

A survey has been employed to examine the above research hypotheses. To do so, we have sourced data from the hospitality industry of Greece, and more specifically from firms located in one of the most-highly visited tourist places, Corfu, the capital of the Ionian Islands region. The data collection was based on a stratified sampling method and was executed through an online survey questionnaire. The firms were selected from the directory of the Corfu Hotels Association and the Federation of Entrepreneurs of Corfu Tourism Enterprises; hence, the diffusion of the online questionnaire was made through forums and social network sites administered by the two professional bodies. The questionnaire was targeted to the person responsible for the firm's social media strategy, usually being the ICT manager or the marketing manager of the firm. Nevertheless, for the very small firms, this role was undertaken by the principal manager or the owner of the hospitality firm. All the potential respondents were informed about the purpose of the research and assured that their answers were anonymous in order to control ex ante for common method bias [81]. The duration of the data collection was approximately three months, resulting in the completion of 106 questionnaires. Non-response bias was assessed by confirming that early and late respondents did not differ significantly in their answers. Two groups of respondents were selected: Those who replied within the first month and those who answered within the third month of data collection. For each construct used in the study, $t$-test comparisons were performed between group means, with results indicating no significant differences among them.

Table 1 shows a summary of the respondents' profile by the criteria: Firm size, firm age, and hospitality sub-sector. Indicatively, $72.1 \%$ of the participating firms included very small firms (1 to 9 employees), while $74.4 \%$ were operating for more than 12 years. Regarding the hospitality sub-sector, $67.4 \%$ of the questionnaires were responded to by hotels, while the rest, $32.6 \%$, concerned small tourist units, such as rentals—apartments, villas, and bungalows.

Table 1. Respondents' profile $(n=106)$.

\begin{tabular}{cccc}
\hline Characteristics & Percentage & Characteristics & Percentage \\
\hline Firms' Size & \multicolumn{3}{c}{ Firms' Years of Operation } \\
\hline 1-9 employees (very small-sized) & $72.1 \%$ & $0-4$ years & $5.8 \%$ \\
10-49 employees (small-sized) & $9.8 \%$ & $4-8$ years & $9.3 \%$ \\
50-250 employees (medium-sized) & $4.7 \%$ & $9-12$ years & $10.5 \%$ \\
More than 250 employees & $3.5 \%$ & More than 12 years & $74.4 \%$ \\
\hline Firms' type & & \\
Hotels & $67.4 \%$ & \\
Other lodges & $32.6 \%$ & \\
\hline
\end{tabular}

\subsection{Measures}

All constructs were assessed by multiple items using a seven-point Likert-type scale, and each item was evaluated on a seven-point Likert scale consisting of strongly disagree (1) to strongly agree (7), excepting firm's size and age, which are used as control variables in the model, as well as the dependent variable of social media adoption. All items used are provided into the Appendix A.

Relative Advantage: A three-item construct $(\alpha=0.951)$ was developed based on Grover (1993) [58], Neo et al. (1994) [59], and Thackeray et al.'s (2008) [82] scales. A sample item for this construct is "The exploitation of social media attributes a competitive advantage to our firm". 
Presence: A three-item construct ( $\alpha=0.934)$ was adopted by Treem and Leonardi (2013) [62]. A sample item for this construct is "Through social media our firm has a presence in the global map of tourist firm".

Interconnections: A three-items construct $(\alpha=0.961)$ was adopted by Treem and Leonardi (2013) [62]. A sample item for this construct is "The exploitation of social media aids our firm to reinforce its loyal customers".

Innovativeness: A three-item construct $(\alpha=0.946)$ was developed based on Damanpour and Wischnevsky (2006) [83] and Grover (1993) [58] scales. A sample item for this construct is "Our firm creates innovative services and packages".

Top management support: A three-item construct $(\alpha=0.944)$ was developed based on Trainor et al. (2014) [84] and Ramdani et al. (2013) [60] scales. A sample item for this construct is "Our firm's top management favors the social media adoption".

External pressure: A three-items construct $(\mathrm{a}=0.900)$ was adopted by Sinclaire and Vogus (2011) [72]. A sample item for this construct is "Our firm has adopted social media due to the previous adoption of social media by other competitive firms".

Environment Uncertainty: A three-items construct $(\mathrm{a}=0.900)$ was adopted by Gordon and Narayanan (1984) [77]. A sample item for this construct is "Our firm experienced a hard competition within the last 5 years".

Social media adoption (SMA): A composite variable was developed, based on Jeyaraj et al.'s (2006) [31] recommendations, to capture more than one dimensions of social media adoption. The composite measure included three variables: (1) The binary variable of 'adoption' (yes/no), (2) the ordinal variable of 'number of social media tools' used, and (3) the ordinal variable of 'years of social media use'.

\section{Results}

Structural Equation Modelling (SEM) was adopted in order to assess the research model introduced in this study, due to the fact that it can measure all paths simultaneously, not stepwise, it is considered a more comprehensive and effective method than stepwise regression analysis [85]. In particular, Partial Least Square (PLS-SEM) path modeling was used to test the hypotheses of the study relying on statistical software Smart PLS 3.0 [86]. The PLS path modelling is a variance-based technique recommended in an early stage of theoretical development in order to test and validate exploratory models $[87,88]$. PLS was selected as it brings together three advantages; first, it is a nonparametric technique and, consequently, does not assume normality of the data and estimates least squares recursively; second, it works well with smaller sample sizes; third, it has a predictive role allowing for planning and future decision making [89-92]. PLS sample size requirements are more relaxed compared to covariance-based techniques. Minimal recommendations for PLS analysis range from 30 to 100 cases $[93,94]$. For a more accurate assessment, conducting power analysis on the proportion of the model with the largest number of predictors $[94,95]$ is recommended. In our case, assuming a large effect size ( $\mathrm{R}^{2}$ equal to or greater than 0.26 ) and using seven first-order predictors to determine the value of the dependent variable, a minimum sample size of 48 cases was required [95].

\subsection{Measurement Model}

A hierarchical second-order factor model was developed in order to examine the hypotheses. The current hierarchical model represents the first-order reflective factors as a set of latent dimensions that operate as formative indicators to second-order factors, namely technological features, organizational features, and environmental features of $[96,97]$. This hierarchical model is different from a conventional correlated factor model, because the inter-correlations among the factors are replaced by a higher-order factor that has paths leading to each of the first-order factors, which are, in turn, represented by their items [98]. The extended repeated indicators approach was adopted in the current model instead of two-stages approach [99]. In the extended repeated indicators approach, all indicators 
of the lower-order components are assigned to the higher-order component. Given that all indicators of the lower-order components are repeated to identify the higher-order component, researchers need to analyze the antecedent constructs' total effect on the higher-order component [99,100].

To ensure the validity of the measures, a confirmatory factor analysis was performed in first-order constructs that are measured in a reflective mode (Table 2). The results of factor loadings exceeded 0.7 [101]. Cronbach $\alpha$ takes acceptable values for each variable, exceeding the recommended levels of 0.8 [102]. Composite reliabilities (CRs) were acceptable, ranging from 0.949 to 0.971 . The average variance extracted (AVE) was also above the threshold of 0.5 [103]. Further, the results of comparison between the square root of the AVE and the highest squared correlation of constructs (Table 3), based on Forner-Larcker Criterion verified the discriminant validity for further analyses [104].

Table 2. Measurement of the model evaluation.

\begin{tabular}{|c|c|c|c|c|c|}
\hline Constructs & Items & Factors Loadings & Cronbach's $\alpha$ & CR & AVE \\
\hline \multirow{3}{*}{ Relative Advantage } & RA1 & 0.935 & & & \\
\hline & RA2 & 0.927 & 0.930 & 0.956 & 0.877 \\
\hline & RA3 & 0.948 & & & \\
\hline \multirow{4}{*}{ Presence } & PRES1 & 0.883 & & & \\
\hline & PRES2 & 0.966 & 0.919 & 0.949 & 0.862 \\
\hline & PRES3 & 0.934 & & & \\
\hline & INTERC1 & 0.949 & & & \\
\hline \multirow[t]{3}{*}{ Interconnection } & INTERC2 & 0.947 & 0.950 & 0.968 & 0.909 \\
\hline & INTERC3 & 0.964 & & & \\
\hline & INNOV1 & 0.949 & & & \\
\hline \multirow[t]{3}{*}{ Innovativeness } & INNOV2 & 0.964 & 0.938 & 0.961 & 0.890 \\
\hline & INNOV3 & 0.917 & & & \\
\hline & TMS1 & 0.934 & & & \\
\hline \multirow[t]{2}{*}{ Top Management Support } & TMS2 & 0.944 & 0.930 & 0.955 & 0.876 \\
\hline & TMS3 & 0.931 & & & \\
\hline \multirow[t]{3}{*}{ External Pressure } & EP1 & 0.956 & 0.955 & 0.971 & 0.917 \\
\hline & $\mathrm{EP} 2$ & 0.969 & & & \\
\hline & EP3 & 0.947 & & & \\
\hline \multirow[t]{3}{*}{ Environment Uncertainty } & UNC1 & 0.894 & 0.900 & 0.937 & 0.833 \\
\hline & UNC2 & 0.925 & & & \\
\hline & UNC3 & 0.918 & & & \\
\hline
\end{tabular}

Note: RA = Relative Advantage, PRES = Presence, INTERC = Interconnections, INNOV = Innovativeness, TMS = Top Management Support, EP = External Pressure, UNC= Environment Uncertainty.

Table 3. Discriminant Validity based on Fornell-Larcker Criterion.

\begin{tabular}{|c|c|c|c|c|c|c|c|}
\hline & 1. & 2. & 3. & 4. & 5. & 6. & 7. \\
\hline 1. External Pressure & 0.957 & & & & & & \\
\hline 2. Innovativeness & 0.206 & 0.944 & & & & & \\
\hline 3. Interconnections & 0.353 & 0.415 & 0.953 & & & & \\
\hline 4. Presence & 0.139 & 0.361 & 0.386 & 0.928 & & & \\
\hline 5. Relative Advantage & 0.304 & 0.351 & 0.856 & 0.426 & 0.937 & & \\
\hline 6. Top Management Support & 0.149 & 0.527 & 0.595 & 0.434 & 0.537 & 0.936 & \\
\hline 7. Environment Uncertainty & 0.321 & 0.288 & 0.427 & 0.389 & 0.485 & 0.387 & 0.913 \\
\hline
\end{tabular}

The validity of the outer model of first-order constructs on second-order constructs was successfully tested following the directions provided by Sarstedt et al. [99] and Ringle et al. [105]. A mixture of the repeated indicator approach and the use of latent variable scores in a two-stage approach was implemented. In the first step, the repeated indicator approach was used to obtain latent variable scores for the first-order constructs, which in the second step served as manifest variables in the measurement model of the higher-order construct. Since each first order construct was composed of three items, there was no bias stemming from an unequal number of indicators $[76,105]$. The path weights of first-order constructs suggested that each component operates as an important determinant of second 
order measurement model's variables $[104,106]$. The variance inflation factor (VIF) was applied to check multicollinearity, that is the effect of collinearity between the predictor variables in a regression model [107]. For formative constructs, acceptable VIF values should be lower than 5 [101,107]. In the current study, all the values are below 5, with the highest VIF value being 3.905 (see Table 4).

Table 4. Means, multicollinearity diagnostics, and path weights of first-order constructs on second-order constructs.

\begin{tabular}{cccc}
\hline Construct & Path Weights & Variance Inflation Factors (VIF) & Means \\
\hline Relative Advantage & 0.390 & 3.905 & 5.338 \\
Presence & 0.333 & 1.224 & 5.548 \\
Interconnection & 0.453 & 3.757 & 5.458 \\
Innovativeness & 0.579 & 1.385 & 4.722 \\
Top Management Support & 0.565 & 1.385 & 4.828 \\
External Pressure & 0.507 & 1.115 & 3.835 \\
Environment Uncertainty & 0.714 & 1.115 & 5.398 \\
\hline
\end{tabular}

\subsection{Structural Model}

The structural model from the PLS-SEM analysis is presented in Figure 1, in which the explained variance of endogenous variables $\left(R^{2}\right)$ and the standardized path coefficients $(\beta)$ are indicated. Contrary to covariance structure analysis modelling approaches that rely on goodness-of-fit measures to evaluate the structural model, in PLS-SEM, the structural model is assessed by examining coefficient of determination $\left(\mathrm{R}^{2}\right)$ values, predictive relevance (Stone-Geisser $\mathrm{Q}^{2}$ ), and the effect size of path coefficients [104]. The statistical significance of estimates (t-statistics) is obtained by a the nonparametric bootstrapping with 5000 resamples $[88,108]$.

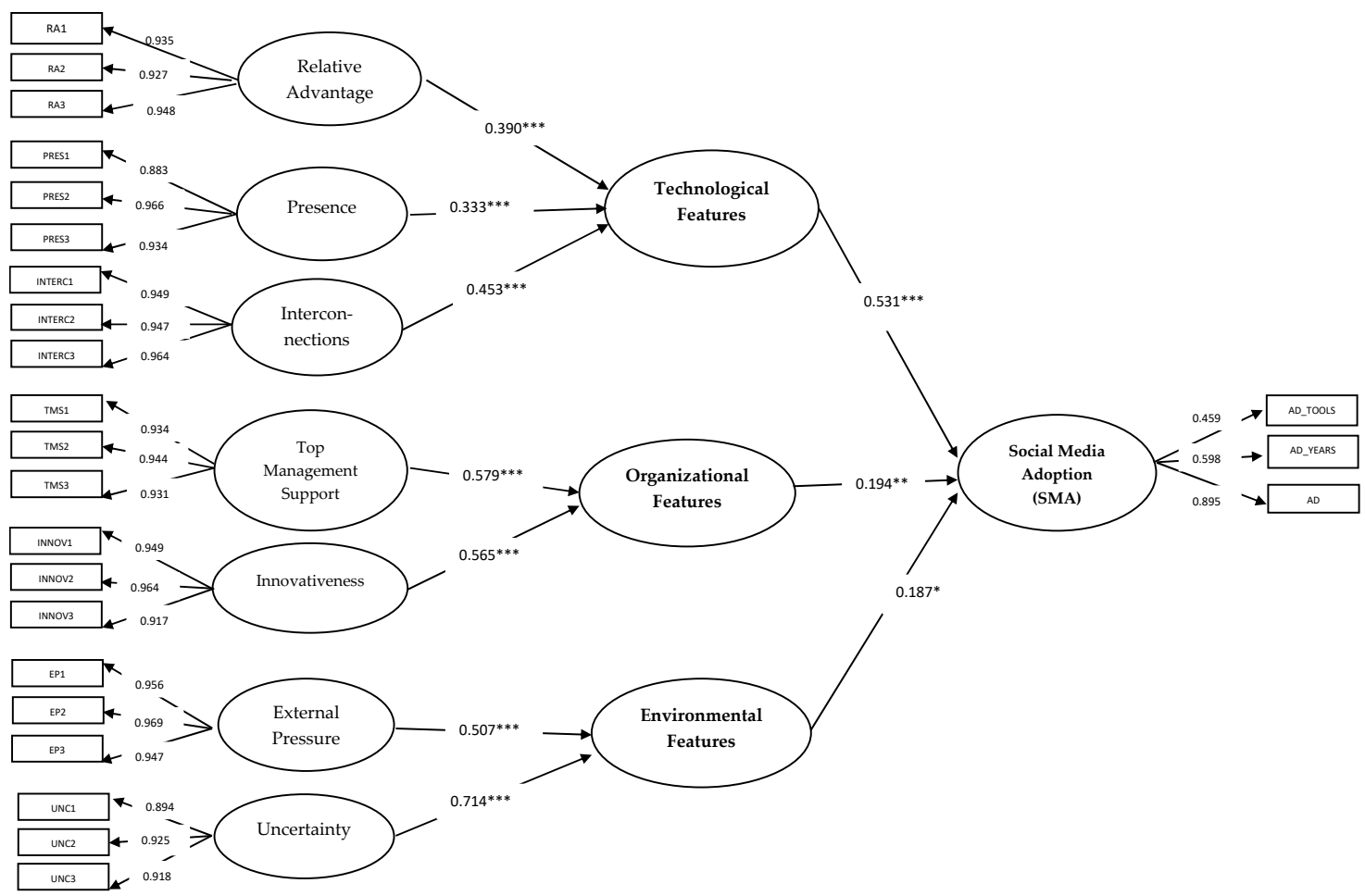

Figure 1. Estimated causal relationships of structural models. Note: ${ }^{* *} p<0.001,{ }^{* *} p<0.01,{ }^{*} p<0.05$.

The structural model explains $99.9 \%$ of the variance in technological features of social media $\left(R^{2}=0.999\right), 100 \%$ of that in organizational features of social media $\left(R^{2}=1.000\right), 99.9 \%$ of that in 
environmental features of social media $\left(R^{2}=0.999\right)$, and $61.5 \%$ of that in social media adoption $\left(R^{2}=0.615\right)$.

The predictive relevance Stone-Geisser $\left(\mathrm{Q}^{2}\right)$ test is a measure of how well observed values are reproduced by the model and its parameter estimates, assessing as such the model's predictive validity through sample re-use [109]. $Q^{2}$ values above zero give evidence that the observed values are well-reconstructed and that the model shows predictive relevance [88]. The blindfolding procedure in the current model demonstrates that technological features $\left(Q^{2}=0.622\right)$, organizational features $\left(Q^{2}=0.668\right)$, environmental features $\left(Q^{2}=0.562\right)$, and social media adoption $\left(Q^{2}=0.254\right)$ have satisfactory predictive relevance [88]. Additional analysis of the composite based standardized root mean square residual (SRMR) yields a value of 0.102 , which is marginally close to the threshold of 0.10 , thus confirming the overall fit of the PLS path model [88,104].

All research hypotheses were supported as shown in Figure 1 and Table 5. Technological features $(b=0.532, p<0.001)$, organizational features $(b=0.194, p<0.010)$, and environmental features $(b=0.187, p<0.050)$ of social media are found to have a statistically significant positive prediction impact on the adoption rate of social media. Likewise, all the first order variables, namely relative advantage $(b=0.207, p<0.001)$, presence $(b=0.177, p<0.001)$, interconnections $(b=0.241, p<0.001)$, top management support $(b=0.112, p<0.001)$, innovativeness $(b=0.110, p<0.001)$, external pressure $(b=0.095, p<0.001)$, and environment uncertainty $(b=0.532, p<0.001)$ exert a statistically significant positive predictive influence on the adoption rate of social media.

Table 5. Partial Least Square-Structural Equation Modelling (PLS-SEM) results.

\begin{tabular}{|c|c|c|c|c|c|}
\hline Hypotheses & Relationships & $\begin{array}{l}\text { Path-Coefficients } \\
\quad \text { (b) }\end{array}$ & $t$ & $p$ & Decisions \\
\hline H1 & Technological Features $\rightarrow$ Social Media Adoption & 0.531 & 6.412 & 0.000 & Supported \\
\hline H1a & $\begin{array}{l}\text { Relative Advantage } \rightarrow \text { Technological } \\
\text { Features } \rightarrow \text { Social media adoption }\end{array}$ & 0.207 & 5.957 & 0.000 & Supported \\
\hline $\mathrm{H} 1 \mathrm{~b}$ & $\begin{array}{c}\text { Presence } \rightarrow \text { Technological Features } \rightarrow \text { Social media } \\
\text { adoption }\end{array}$ & 0.177 & 4.307 & 0.000 & Supported \\
\hline H1c & $\begin{aligned} \text { Interconnections } & \rightarrow \text { Technological Features } \rightarrow \text { Social } \\
& \text { media adoption }\end{aligned}$ & 0.241 & 6.005 & 0.000 & Supported \\
\hline $\mathrm{H} 2$ & Organizational Features $\rightarrow$ Social media adoption & 0.194 & 2.693 & 0.007 & Supported \\
\hline $\mathrm{H} 2 \mathrm{a}$ & $\begin{array}{c}\text { Top Management Support } \rightarrow \text { Organizational } \rightarrow \text { Social } \\
\text { media adoption }\end{array}$ & 0.112 & 2.622 & 0.009 & Supported \\
\hline $\mathrm{H} 2 \mathrm{~b}$ & $\begin{array}{c}\text { Innovativeness } \rightarrow \text { Organizational Features } \rightarrow \text { Social } \\
\text { media adoption }\end{array}$ & 0.110 & 2.658 & 0.008 & Supported \\
\hline H3 & Environmental Features $\rightarrow$ Social media adoption & 0.187 & 2.264 & 0.024 & Supported \\
\hline H3a & $\begin{array}{c}\text { External Pressure } \rightarrow \text { Environmental Features } \rightarrow \text { Social } \\
\text { media adoption }\end{array}$ & 0.095 & 2.304 & 0.021 & Supported \\
\hline $\mathrm{H} 3 \mathrm{~b}$ & $\begin{array}{l}\text { Environment Uncertainty } \rightarrow \text { Environmental } \\
\text { Features } \rightarrow \text { Social media adoption }\end{array}$ & 0.134 & 2.146 & 0.032 & Supported \\
\hline
\end{tabular}

\section{Discussion and Future Research}

\subsection{Research Implications}

In light of the ever-increasing use of social media in the tourism sector and the relevantly limited prior empirical research on their adoption in the hospitality industry, this paper has developed and tested a rather comprehensive research model that provides the prime antecedents of social media adoption by hospitality firms. The goal of this study is to assess the determinants of social media adoption by using an integrative lens that combines the innovation characteristics of social media and the technology, organization, and environment perspectives of the organization. The results show that there are seven factors that influence the adoption of organizational social media adoption, that are grouped into three groups. The prime determinants include three technological features of social media, also referring to the innovation potential of this technology, which are: (1) Relative advantage, (2) presence, and (3) interconnections. Two organizational features also have a quite significant influence on social media adoption, namely (4) top management support and (5) innovativeness. Last, but not least, there are two factors concerning the external environment that have a rather great effect on social media adoption, that are (6) external pressure and (7) environment uncertainty. 
Out of the three groups of factors, technological features are considered as the most important ones. Previous research studies in the field of SMA in the hospitality industry have mostly investigated and emphasized on the power of organizational features [43,45], while other studies have found out that the technological context has insignificant influence on SMA [21,44]. This study contributes to ongoing research on organizational SMA by indicating that technological features are the most important determinants, while the organizational and environmental context are less significant. The selection of most prominent features, which also concern abilities provided by social media, that are presence, interconnections, and relative advantage, has possibly contributed to this finding. Firms able to identify potential value gained by social media use in terms of enhancing firm's visibility (e.g., via Facebook and Instagram), increasing its communication with customers and partners (e.g., via TripAdvisor), and obtaining competitive advantage (e.g., via the provision of innovative services, such as those provided by Alexa for Hospitality) are those that have the greater possibilities for using social media. Instead, firms that have not recognized these technological features are less likely to make extensive use of social media, even if their organizational conditions are favorable or their external environment urges them to do so.

Out of the three technological features, the potential of social media to develop new 'interconnections' is found to be the most significant factor affecting social media adoption, while 'relative advantage' and 'presence' follow in significance. While the importance of relative advantage and presence have been raised by prior studies [34], the 'interconnections' feature has not been adequately neither discussed nor empirically tested in the social media adoption field. Hence, this study has contributed to ongoing social media research, and basically empirical research at organizational level, with the identification of one prime antecedent, that is the ability of social media to enable firms to develop associations with either customers or partners or supplier or peers (competitors), and hence develop their business network.

Concerning the organizational features, so far, the organizational innovation adoption theory has identified the great influence of 'top management support' [31]. While managerial support has been examined as part of the TOE framework and identified as prime antecedent of tourism firms' attitude towards social media marketing, 'innovativeness' has been primarily examined as part of the DIT framework and has been recognized as an important influencer of sustainability innovation adoption by hotels/resorts. By combining the two theoretical frameworks, this study has resulted in identifying the significant effect of both these factors on social media adoption in the hospitality industry. This finding is important for both the hospitality management literature as well as for the organizational innovation adoption area, since 'innovativeness' attracts interest in being investigated as generic determinant of organizational innovation adoption.

Regarding the environmental features, 'external pressure' has been reported as highly significant determinant of organizational innovation adoption [31]. In the hospitality management literature, 'external pressure' has been found to have a significant impact on hotel's ICT adoption [42]. Regarding the organizational use of social media, the perceived level of competition, which is partly measured by 'environment uncertainty', has also been identified as having an influence, even if it is weak, on the adoption [34]. Our empirical findings have revealed the great role that both these two factors, mostly 'external pressure', but also 'environment uncertainty', have on social media adoption by firms of the hospitality industry. This finding is important for both the hospitality management as well as the organizational innovation adoption literature, since 'environment uncertainty' could be investigated as a generic determinant of organizational innovation adoption no matter whether this concerns social media or other innovative tools and practices.

In addition, the paper has contributed to the development of an aggregated construct, which includes not only adoption, measured as binary variable, but also intensity of adoption, measured by the number of social media tools used, and time of adoption, measured by the years of social media use. DIT framework [31] urges researchers towards using dependent variables that capture actual system use and adoption, rather than intention to adopt, in order to overcome the 
self-reporting bias that is inherence in perceived scales. The proposed aggregate construct can be used as either dependent or even independent variable in future research studies for providing valid and reliable data on social media actual use.

Overall, the present study brings new knowledge in the hospitality research area by shedding light on the primary factors that affect hospitality firms' decision not only to adopt, but primarily to make extensive use of social media. These factors relate to the abilities provided by social media tools (relative advantage, presence-visibility, interconnections) combined with a favorable organizational environment, illustrated by innovative culture and top management support, and a rather challenging external environment that exerts pressure on them to follow technological trends and innovate. As a result, it stresses the need for researchers and practitioners to address the social media strategy issues faced by hospitality firms through an integrated approach, rather than focusing on isolated factors that could enhance their propensity to use a specific social media tool (e.g., Instagram).

\subsection{Practical Implications}

For decision makers in the hospitality industry considering the use of social media apps and practices, the findings provide a sound basis for gauging the direct and indirect effects of the innovation characteristics of social media. In evaluating this relatively recent technology, our study highlights the importance of assessing the innovation characteristics against the organization and environment context of the organization before adopting social media apps and practices. Specifically, our findings indicate that full exploitation of the innovation features of SM, that are relative advantage, presence, and interconnections, can enhance firms' degree of adoption. However, SMA combines with firms' innovation performance and managerial support. Hence, practitioners have to invest in developing their innovation culture as well as increasing their innovation rates in terms of both adopting and implementing innovation for their customers. It seems that there is a fit between innovation culture and technology adoption. Even in the presence of competitive and peer pressure, as well as environment uncertainty, without weighing the innovativeness level and top management support within the firm, the relative advantage, the visibility, and the interconnection benefits of social media may fail to translate into economic value for the organization. Modernization trend or mimetic behavior can possibly contribute to adoption of social media practices, but cannot solely drive their enhanced adoption and their full exploitation. External pressure and competition intensity can trigger, but cannot drive themselves to, social media adoption. Hence, practitioners should invest in building an innovative culture within their firm, resulting in increase of the firm's innovativeness, as well as assuring top management support. To achieve that, they have to try to increase the level of top management knowledge about social media's value and potential for improving their firms' innovativeness and overall performance. The proposed research model could be used to examine social media adoption in other sub-sectors of the tourism industry, such as transport, tourism intermediaries (agencies and tour operators), catering, etc. This would enable public and private stakeholders, who have the role of tourism policy makers, to make informed decisions on how organizations could be encouraged and reinforced to implement social media as well as other innovation-related technologies and business practices $[56,78]$.

\subsection{Future Research}

The present study has several limitations that future research can address. First, the current study employed the firm as a unit of analysis and examined the organizational SMA. Future research could adopt the business unit or the function as unit of analysis and investigate which factors affect the use and increase of benefits of social media for achieving specific functional goals, e.g., extending customer reach, enhancing customer retention, creating innovative services, spotting new suppliers and partners, etc.

Our empirical survey has been restricted to include data derived by hospitality firms (hotels, small tourist units) located in Corfu, Greece. Current research design has not made any discrimination 
in social media adoption between luxury and economy hotels or between chain and independent hotels. Future research should adopt one or more classification systems, used to rate hospitality establishment on services, facilities, and overall experience (e.g., star classification for hotels, key classification for other tourist accommodation units) and investigate factors that could discriminate the extent (number of different tools, years of adoption) to which they use social media.

Future empirical studies could also be targeted towards improving the generalizability of our results by investigating the present research framework in a wider population located in different geographical tourist areas. Given that cultural values may influence the firms' inclination towards using social media, between Web 2.0 ICTs and SMA, conducting a cross-cultural study is considered of high research interest and potential contribution for the hospitality management area.

The above research model could be extended to include the impact of SMA on hospitality firms' performance. Such an extension would enable firms to identify factors that not only drive adoption, but also enhance the value that firms capture from social media to achieve their strategic goals and improve their position in the worldwide hospitality industry.

Another challenging stream of research concerns the examination of the model's fit and power for estimating the sustainable development status of hospitality firms. As mentioned in the theoretical background section, the DIT framework has been applied to identify factors that affect the adoption of environment-friendly and sustainability practices for the hospitality industry $[34,35]$. Our study could inform this ongoing research with the aim of developing a comprehensive model with key determinant factors of hospitality firms' sustainability performance. The model could include innovation-related factors concerning both technological (e.g., digital technologies) as well as business (e.g., innovative processes) practices that a firm may employ towards achieving its sustainability strategy. For instance, a future research model could combine innovation features derived from the implementation of certain digital technologies (e.g., reservation systems, social media, mobile check-in applications, sensor-activated systems) with those provided by certain environment friendly practices (e.g., water recycling, energy conservation, guestroom sustainability) to examine the sustainability development status of firms in the hospitality industry [110].

Author Contributions: Methodology, A.P. and N.M.; supervision, A.P.; writing—original draft preparation, A.P. and N.M.; data analysis, A.P. and N.M.; software, N.M.; data collection and entry, A.S. All authors have read and agreed to the published version of the manuscript.

Funding: This research received no external funding.

Acknowledgments: The authors are grateful to the Corfu Hotels Association and the Federation of Entrepreneurs of Corfu Tourism Enterprises for their support in the data collection.

Conflicts of Interest: The authors declare no conflict of interest

Appendix A

\begin{tabular}{ccc}
\hline Constructs & \multicolumn{1}{c}{ Items } \\
\hline \multirow{2}{*}{ Relative Advantage } & RA1 & The strategic goal of our firm is achieved more easily using social media. \\
\cline { 2 - 3 } Presence & RA2 & Through social media the firm desires to improve its provided services. \\
\cline { 2 - 3 } & RA3 & The exploitation of social media attributes a competitive advantage to our firm. \\
\cline { 2 - 3 } & PRES1 & Through social media our firm has a presence in the global map of tourist firm. \\
\hline PRES2 & ORES3 & Social media exploitation gives our firm the ability to attract new customers. \\
\cline { 2 - 3 } & INTER1 & The exploitation of social media aids our firm to reinforce its loyal customers. \\
\cline { 2 - 3 } & INTER2 & The use of social media makes our firm to be associated with other firms. \\
\hline INTER3 & The exploitation of social media expands our firm's network and contacts. \\
\hline
\end{tabular}




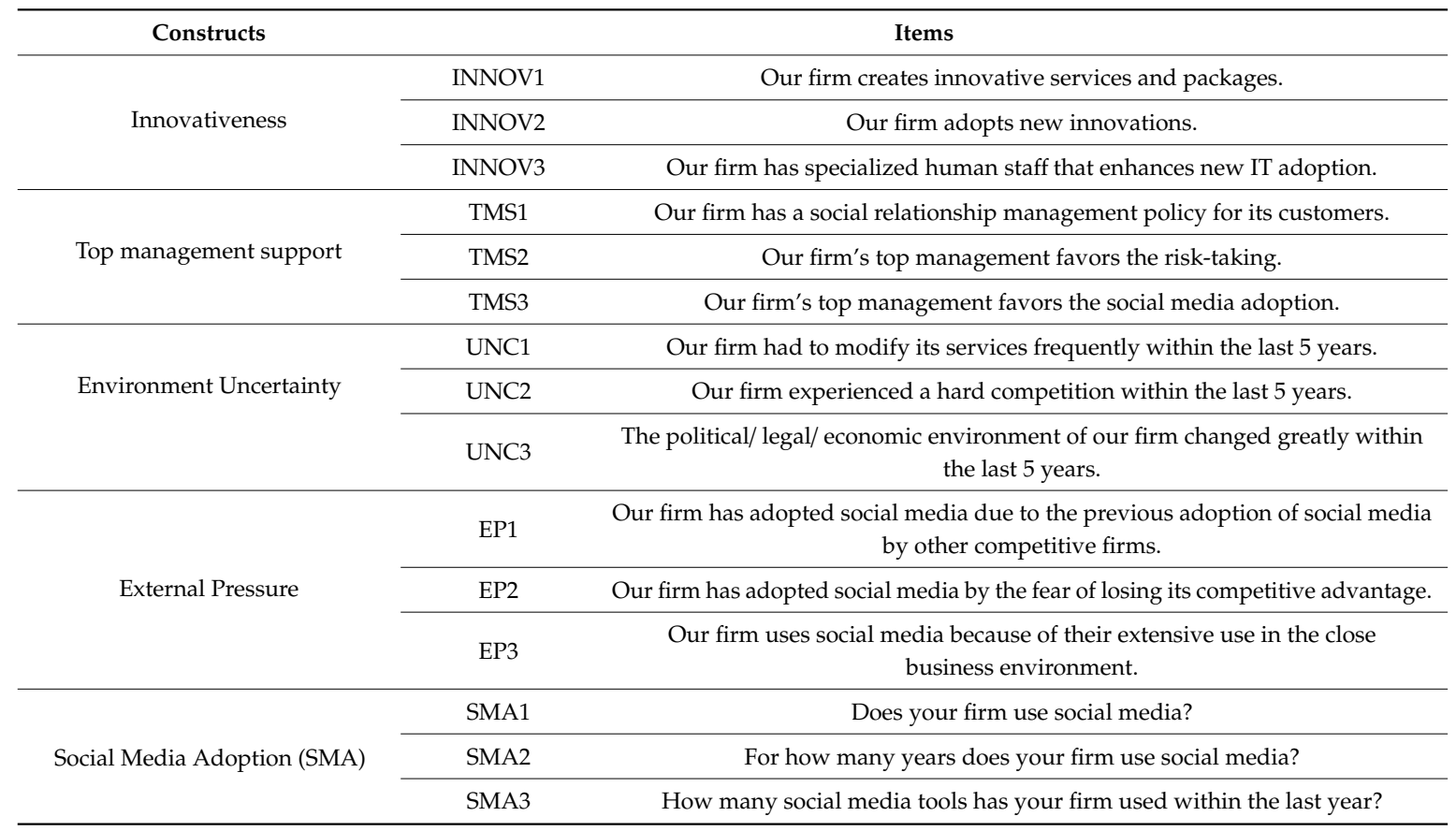

\section{References}

1. Werthner, H.; Ricci, F. E-commerce and tourism. Commun. ACM 2004, 47, 101-105. [CrossRef]

2. Marcussen, C.H. Trends in European Internet Distribution of Travel and Tourism Services; Centre for Regional and Tourism Research: Stenbrudsvej, Denmark, 2008.

3. Hvass, K.A.; Munar, A.M. The takeoff of social media in tourism. J. Vacat. Mark. 2012, 18, 93-103. [CrossRef]

4. Zeng, B. Social media in tourism. J. Tour. Hosp. 2013, 2, 1-2. [CrossRef]

5. Vickery, G.; Wunsch-Vincent, S. Participative Web and User-Created Content: Web 2.0 Wikis and Social Networking; Organization for Economic Cooperation and Development (OECD): Paris, France, 2007.

6. Ho, C.-W.; Wang, Y.-B. Does Social Media Marketing and Brand Community Play the Role in Building a Sustainable Digital Business Strategy? Sustainability 2020, 12, 6417. [CrossRef]

7. Buhalis, D. eTourism: Information Technology for Strategic Tourism Management; Pearson Education: London, UK, 2003.

8. Inversini, A.; Masiero, L. Selling rooms online: The use of social media and online travel agents. Int. J. Contemp. Hosp. Manag. 2014, 26, 272-292. [CrossRef]

9. Tajvidi, R.; Karami, A. The effect of social media on firm performance. Comput. Hum. Behav. 2017, 105174. [CrossRef]

10. Chan, N.L.; Guillet, B.D. Investigation of social media marketing: How does the hotel industry in Hong Kong perform in marketing on social media websites? J. Travel Tour. Mark. 2011, 28, 345-368. [CrossRef]

11. Roberts, D.L.; Candi, M. Leveraging social network sites in new product development: Opportunity or hype? J. Prod. Innov. Manag. 2014, 31, 105-117. [CrossRef]

12. Tajeddini, K.; Trueman, M. Managing Swiss Hospitality: How cultural antecedents of innovation and customer-oriented value systems can influence performance in the hotel industry. Int. J. Hosp. Manag. 2012, 31, 1119-1129. [CrossRef]

13. Chatzigeorgiou, C.; Christou, E. Adoption of social media as distribution channels in tourism marketing: A qualitative analysis of consumers' experiences. J. Tour. Herit. Serv. Mark. 2020, 6, 25-32. [CrossRef]

14. Melián-González, S.; Bulchand-Gidumal, J. A model that connects information technology and hotel performance. Tour. Manag. 2016, 53, 30-37. [CrossRef]

15. Escobar-Rodríguez, T.; Carvajal-Trujillo, E. An evaluation of Spanish hotel websites: Informational vs. relational strategies. Int. J. Hosp. Manag. 2013, 33, 228-239. [CrossRef]

16. Garrido-Moreno, A.; García-Morales, V.J.; Lockett, N.; King, S. The missing link: Creating value with Social Media use in hotels. Int. J. Hosp. Manag. 2018, 75, 94-104. [CrossRef] 
17. Munar, A.M.; Jacobsen, J.K.S. Trust and involvement in tourism social media and web-based travel information sources. Scand. J. Hosp. Tour. 2013, 13, 1-19. [CrossRef]

18. Chung, T.; Law, R. Developing a performance indicator for hotel websites. Int. J. Hosp. Manag. 2003, 22, 119-125. [CrossRef]

19. Akehurst, G. User generated content: The use of blogs for tourism organisations and tourism consumers. Serv. Bus. 2009, 3, 51. [CrossRef]

20. Yoo, K.-H.; Lee, Y.; Gretzel, U.; Fesenmaier, D.R. Trust in travel-related consumer generated media. Inf. Commun. Technol. Tour. 2009, 2009, 49-59.

21. Gangwar, H.; Date, H.; Raoot, A.D. Review on IT adoption: Insights from recent technologies. J. Enterp. Inf. Manag. 2014, 27, 488-502. [CrossRef]

22. Hudson, S.; Thal, K. The impact of social media on the consumer decision process: Implications for tourism marketing. J. Travel Tour. Mark. 2013, 30, 156-160. [CrossRef]

23. Harrigan, P.; Evers, U.; Miles, M.; Daly, T. Customer engagement with tourism social media brands. Tour. Manag. 2017, 59, 597-609. [CrossRef]

24. Roberts, P.W.; Amit, R. The dynamics of innovative activity and competitive advantage: The case of Australian retail banking, 1981 to 1995. Organ. Sci. 2003, 14, 107-122. [CrossRef]

25. Tornatzky, L.G.; Fleischer, M.; Chakrabarti, A.K. Processes of Technological Innovation; Lexington books: Lanham, MD, USA, 1990.

26. Min, S.; So, K.K.F.; Jeong, M. Consumer adoption of the Uber mobile application: Insights from diffusion of innovation theory and technology acceptance model. J. Travel Tour. Mark. 2019, 36, 770-783. [CrossRef]

27. Rogers, E.M. Diffusion of preventive innovations. Addict. Behav. 2002, 27, 989-993. [CrossRef]

28. Rogers, E.M. Diffusion of Innovations, 5th ed.; Free Press: New York, NY, USA, 2003.

29. Damanpour, F.; Evan, W.M. Organizational Innovation and Performance: The Problem of "Organizational Lag". Adm. Sci. Q. 1984, 29, 392-409. [CrossRef]

30. Premkumar, G.; Ramamurthy, K. The Role of Interorganizational and Organizational Factors on the Decision Mode for Adoption of Interorganizational Systems*. Decis. Sci. 1995, 26, 303-336. [CrossRef]

31. Jeyaraj, A.; Rottman, J.W.; Lacity, M.C. A review of the predictors, linkages, and biases in IT innovation adoption research. J. Inf. Technol. 2006, 21, 1-23. [CrossRef]

32. Rogers, E. Diffusion of Innovations, 4th ed.; The Free Press: New York, NY, USA, 1995.

33. Hashim, N.H.; Murphy, J.; Purchase, S.; O'Connor, P. Website and email adoption by Malaysian hotels. Int. J. Hosp. Manag. 2010, 29, 194-196. [CrossRef]

34. Le, Y.; Hollenhorst, S.; Harris, C.; McLaughlin, W.; Shook, S. Environmental management: A study of Vietnamese hotels. Ann. Tour. Res. 2006, 33, 545-567. [CrossRef]

35. Smerecnik, K.R.; Andersen, P.A. The diffusion of environmental sustainability innovations in North American hotels and ski resorts. J. Sustain. Tour. 2011, 19, 171-196. [CrossRef]

36. Clarke, T.B.; Murphy, J.; Adler, J. Celebrity chef adoption and implementation of social media, particularly pinterest: A diffusion of innovations approach. Int. J. Hosp. Manag. 2016, 57, 84-92. [CrossRef]

37. Peres, R.; Muller, E.; Mahajan, V. Innovation diffusion and new product growth models: A critical review and research directions. Int. J. Res. Mark. 2010, 27, 91-106. [CrossRef]

38. Hwang, B.-N.; Huang, C.-Y.; Wu, C.-H. A TOE Approach to Establish a Green Supply Chain Adoption Decision Model in the Semiconductor Industry. Sustainability 2016, 8, 168. [CrossRef]

39. Chiu, C.-Y.; Chen, S.; Chen, C.-L. An integrated perspective of TOE framework and innovation diffusion in broadband mobile applications adoption by enterprises. Int. J. Manag. Econ. Soc. Sci. IJMESS 2017, 6, 14-39.

40. Pateli, A.; Mikalef, P. Configurations explaining Social Media's Impact on Innovation Performance. In Proceedings of the Pacific Asia Conference on Information Systems, Langkawi, Malaysia, 16-20 July 2017.

41. Ahmad, S.Z.; Abu Bakar, A.R.; Ahmad, N. Social media adoption and its impact on firm performance: The case of the UAE. Int. J. Entrep. Behav. Res. 2019, 25, 84-111. [CrossRef]

42. Leung, D.; Lo, A.; Fong, L.H.N.; Law, R. Applying the Technology-Organization-Environment framework to explore ICT initial and continued adoption: An exploratory study of an independent hotel in Hong Kong. Tour. Recreat. Res. 2015, 40, 391-406. [CrossRef]

43. Wang, Y.-S.; Li, H.-T.; Li, C.-R.; Zhang, D.-Z. Factors affecting hotels' adoption of mobile reservation systems: A technology-organization-environment framework. Tour. Manag. 2016, 53, 163-172. [CrossRef] 
44. Ndekwa, A.G.; Katunzi, T.M. Small and medium tourist enterprises and social media adoption: Empirical evidence from Tanzanian tourism sector. Int. J. Bus. Manag. 2016, 11, 71. [CrossRef]

45. Matikiti, R.; Mpinganjira, M.; Roberts-Lombard, M. Application of the Technology Acceptance Model and the Technology-Organisation-Environment Model to examine social media marketing use in the South African tourism industry. S. Afr. J. Inf. Manag. 2018, 20, 1-12. [CrossRef]

46. Oliveira, T.; Martins, M.F. Literature review of information technology adoption models at firm level. Electron. J. Inf. Syst. Eval. 2011, 14, 110.

47. Hsu, P.-F.; Kraemer, K.L.; Dunkle, D. Determinants of e-business use in US firms. Int. J. Electron. Commer. 2006, 10, 9-45. [CrossRef]

48. Awa, H.O.; Ojiabo, O.U. A model of adoption determinants of ERP within T-O-E framework. Inf. Technol. People 2016, 29, 901-930. [CrossRef]

49. Baker, J. The technology-organization-environment framework. In Information Systems Theory; Springer: Berlin/Heidelberg, Germany, 2012; pp. 231-245.

50. Penttinen, E.; Tuunainen, V.K. Assessing the Effect of External Pressure in Inter-organizational IS Adoption-Case Electronic Invoicing. In Exploring the Grand Challenges for Next Generation E-Business; Sharman, R., Rao, H.R., Raghu, T.S., Eds.; Springer: Berlin, Heidelberg, 2011; pp. 269-278.

51. Iacovou, C.L.; Benbasat, I.; Dexter, A.S. Electronic data interchange and small organizations: Adoption and impact of technology. Mis Q. 1995, 1995, 465-485. [CrossRef]

52. Mishra, A.N.; Konana, P.; Barua, A. Antecedents and consequences of internet use in procurement: An empirical investigation of US manufacturing firms. Inf. Syst. Res. 2007, 18, 103-120. [CrossRef]

53. Lutfi, A.A.; Md Idris, K.; Mohamad, R. AIS usage factors and impact among Jordanian SMEs: The moderating effect of environmental uncertainty. J. Adv. Res. Bus. Manag. Stud. 2017, 6, 24-38.

54. Fotis, J.N.; Buhalis, D.; Rossides, N. Social Media Use and Impact during the Holiday Travel Planning Process; Springer: Berlin/Heidelberg, Germany, 2012.

55. Zeng, B.; Gerritsen, R. What do we know about social media in tourism? A review. Tour. Manag. Perspect. 2014, 10, 27-36. [CrossRef]

56. Michaelidou, N.; Siamagka, N.T.; Christodoulides, G. Usage, barriers and measurement of social media marketing: An exploratory investigation of small and medium B2B brands. Ind. Mark. Manag. 2011, 40, 1153-1159. [CrossRef]

57. Parveen, F. Impact of Social Media Usage On Organizations. In Proceedings of the Pacific Asia Conference on Information Systems (PACIS), Ho Chi Minh City, Vietnam, 15 July 2012; p. 192.

58. Grover, V. An Empirically Derived Model for the Adoption of Customer-based Interorganizational Systems* Decis. Sci. 1993, 24, 603-640. [CrossRef]

59. Neo, B.-S.; Khoo, P.E.; Ang, S. The Adoption of TradeNet by the Trading Community: An Empirical Analysis. In Proceedings of the ICIS; 1994; pp. 159-174. Available online: https://aisel.aisnet.org/icis1994/58 (accessed on 28 August 2020).

60. Ramdani, B.; Chevers, D.; Williams, D.A. SMEs' adoption of enterprise applications: A technology-organisation-environment model. J. Small Bus. Enterp. Dev. 2013, 20, 735-753. [CrossRef]

61. Moore, G.C.; Benbasat, I. Development of an instrument to measure the perceptions of adopting an information technology innovation. Inf. Syst. Res. 1991, 2, 192-222. [CrossRef]

62. Treem, J.W.; Leonardi, P.M. Social media use in organizations: Exploring the affordances of visibility, editability, persistence, and association. Ann. Int. Commun. Assoc. 2013, 36, 143-189. [CrossRef]

63. Stankov, U.; Lazic, L.; Dragicevic, V. The extent of use of basic Facebook user-generated content by the national tourism organizations in Europe. Eur. J. Tour. Res. 2010, 3, 105-113.

64. Wellman, B.; Haase, A.Q.; Witte, J.; Hampton, K. Does the Internet increase, decrease, or supplement social capital? Social networks, participation, and community commitment. Am. Behav. Sci. 2001, 45, 436-455. [CrossRef]

65. Barbe, D.; Pennington-Gray, L. Using situational crisis communication theory to understand Orlando hotels' Twitter response to three crises in the summer of 2016. J. Hosp. Tour. Insights 2018, 1, 258-275. [CrossRef]

66. Sharif, M.H.M.; Davidson, R.; Troshani, I. Exploring Social Media Adoption in Australian Local Government Organizations. In Proceedings of the CONF-IRM, Auckland, New Zealand, 4 January 2013; p. 29.

67. Dahnil, M.I.; Marzuki, K.M.; Langgat, J.; Fabeil, N.F. Factors Influencing SMEs Adoption of Social Media Marketing. Procedia Soc. Behav. Sci. 2014, 148, 119-126. [CrossRef] 
68. Hurt, H.T.; Joseph, K.; Cook, C.D. Scales for the measurement of innovativeness. Hum. Commun. Res. 1977, 4, 58-65. [CrossRef]

69. Agarwal, R.; Prasad, J. A conceptual and operational definition of personal innovativeness in the domain of information technology. Inf. Syst. Res. 1998, 9, 204-215. [CrossRef]

70. Wang, Y.; Qualls, W. Towards a theoretical model of technology adoption in hospitality organizations. Int. J. Hosp. Manag. 2007, 26, 560-573. [CrossRef]

71. Fuchs, M.; Höpken, W.; Föger, A.; Kunz, M. E-business readiness, intensity, and impact: An Austrian destination management organization study. J. Travel Res. 2010, 49, 165-178. [CrossRef]

72. Sinclaire, J.K.; Vogus, C.E. Adoption of social networking sites: An exploratory adaptive structuration perspective for global organizations. Inf. Technol. Manag. 2011, 12, 293-314. [CrossRef]

73. Zhu, K.; Kraemer, K.; Xu, S. Electronic business adoption by European firms: A cross-country assessment of the facilitators and inhibitors. Eur. J. Inf. Syst. 2003, 12, 251-268. [CrossRef]

74. Wang, S.; Cheung, W. E-business adoption by travel agencies: Prime candidates for mobile e-business. Int. J. Electron. Commer. 2004, 8, 43-63. [CrossRef]

75. Aragón-Correa, J.A.; Sharma, S. A contingent resource-based view of proactive corporate environmental strategy. Acad. Manag. Rev. 2003, 28,71-88. [CrossRef]

76. Mikalef, P.; Pateli, A. Information technology-enabled dynamic capabilities and their indirect effect on competitive performance: Findings from PLS-SEM and fsQCA. J. Bus. Res. 2017, 70, 1-16. [CrossRef]

77. Gordon, L.A.; Narayanan, V.K. Management accounting systems, perceived environmental uncertainty and organization structure: An empirical investigation. Acc. Organ. Soc. 1984, 9, 33-47. [CrossRef]

78. Smith, K.G.; Grimm, C.M.; Gannon, M.J. Dynamics of Competitive Strategy; Sage Publications, Inc.: Thousand Oaks, CA, USA, 1992.

79. Teece, D.J. Explicating dynamic capabilities: The nature and microfoundations of (sustainable) enterprise performance. Strat. Mgmt. J. 2007, 28, 1319-1350. [CrossRef]

80. Zahra, S.A.; Bogner, W.C. Technology strategy and software new ventures' performance: Exploring the moderating effect of the competitive environment. J. Bus. Ventur. 2000, 15, 135-173. [CrossRef]

81. Chang, S.-J.; Van Witteloostuijn, A.; Eden, L. From the Editors: Common Method Variance in International Business Research; Springer: Berlin/Heidelberg, Germany, 2010.

82. Thackeray, R.; Neiger, B.L.; Hanson, C.L.; McKenzie, J.F. Enhancing promotional strategies within social marketing programs: Use of Web 2.0 social media. Health Promot. Pract. 2008, 9, 338-343. [CrossRef]

83. Damanpour, F.; Wischnevsky, D. Research on innovation in organizations: Distinguishing innovation-generating from innovation-adopting organizations. J. Eng. Technol. Manag. 2006, 23, 269-291. [CrossRef]

84. Trainor, K.J.; Andzulis, J.M.; Rapp, A.; Agnihotri, R. Social media technology usage and customer relationship performance: A capabilities-based examination of social CRM. J. Bus. Res. 2014, 67, 1201-1208. [CrossRef]

85. Jung, H.S.; Yoon, H.H. How Does Workplace Romance Influence Employee Performance in the Hospitality Industry? Sustainability 2020, 12, 5478. [CrossRef]

86. Ringle, C.M.; Wende, S.; Becker, J.-M. SmartPLS 3. Hamburg: SmartPLS. Acad. Manag. Rev. 2014, 9, 419-445.

87. Secondi, L.; Meseguer-Santamaría, M.L.; Mondéjar-Jiménez, J.; Vargas-Vargas, M. Influence of tourist sector structure on motivations of heritage tourists. Serv. Ind. J. 2011, 31, 1659-1668. [CrossRef]

88. Henseler, J.; Ringle, C.M.; Sinkovics, R.R. The use of partial least squares path modeling in international marketing. In New Challenges to International Marketing; Emerald Group Publishing Limited: Bingley, UK, 2009.

89. Afthanorhan, W. Hierarchical component using reflective-formative measurement model in partial least square structural equation modeling (Pls-Sem). Int. J. Math. 2014, 2, 33-49.

90. Falk, R.F.; Miller, N.B. A Primer for Soft Modeling; University of Akron Press: Akron, OH, USA, 1992.

91. Ruiz, D.M.; Gremler, D.D.; Washburn, J.H.; Carrión, G.C. Service value revisited: Specifying a higher-order, formative measure. J. Bus. Res. 2008, 61, 1278-1291. [CrossRef]

92. García-Pozo, A.; Mondéjar-Jiménez, J.; Sánchez-Ollero, J.L. Internet's User Perception of Corporate Social Responsibility in Hotel Services. Sustainability 2019, 11, 2916. [CrossRef]

93. Gefen, D.; Straub, D.; Boudreau, M.-C. Structural equation modeling and regression: Guidelines for research practice. Commun. Assoc. Inf. Syst. 2000, 4, 7. [CrossRef] 
94. Chin, W.W.; Newsted, P.R. Structural equation modeling analysis with small samples using partial least squares. Stat. Strateg. Small Sample Res. 1999, 1, 307-341.

95. Green, S.B. How many subjects does it take to do a regression analysis. Multivar. Behav. Res. 1991, 26, 499-510. [CrossRef]

96. Keeping, L.M.; Levy, P.E. Performance appraisal reactions: Measurement, modeling, and method bias. J. Appl. Psychol. 2000, 85, 708. [CrossRef]

97. Prajogo, D.I.; Cooper, B.K. The effect of people-related TQM practices on job satisfaction: A hierarchical model. Prod. Plan. Control 2010, 21, 26-35. [CrossRef]

98. Parker, C.P. A test of alternative hierarchical models of psychological climate: PCg, satisfaction, or common method variance? Organ. Res. Methods 1999, 2, 257-274. [CrossRef]

99. Sarstedt, M.; Hair, J.F., Jr.; Cheah, J.-H.; Becker, J.-M.; Ringle, C.M. How to specify, estimate, and validate higher-order constructs in PLS-SEM. Australas. Mark. J. 2019, 27, 197-211. [CrossRef]

100. Becker, J.-M.; Klein, K.; Wetzels, M. Hierarchical latent variable models in PLS-SEM: Guidelines for using reflective-formative type models. Long Range Plan. 2012, 45, 359-394. [CrossRef]

101. Hair, J.F., Jr.; Hult, G.T.M.; Ringle, C.; Sarstedt, M. A Primer on Partial Least Squares Structural Equation Modeling; Sage Publications: Thousand Oaks, CA, USA, 2016.

102. Gefen, D.; Straub, D. A practical guide to factorial validity using PLS-Graph: Tutorial and annotated example. Commun. Assoc. Inf. Syst. 2005, 16, 5. [CrossRef]

103. Fornell, C.; Larcker, D.F. Evaluating structural equation models with unobservable variables and measurement error. J. Mark. Res. 1981, 18, 39-50. [CrossRef]

104. Hair, J.; Sarstedt, M.; Hopkins, L.; Kuppelwieser, G.V. Partial least squares structural equation modeling (PLS-SEM): An emerging tool in business research. Eur. Bus. Rev. 2014, 26, 106-121. [CrossRef]

105. Ringle, C.M.; Sarstedt, M.; Straub, D.W. A critical look at the use of PLS-SEM in MIS quarterly. MIS Q. Manag. Inf. Syst. 2012, 36, iii-xiv. [CrossRef]

106. Kim, G.; Shin, B.; Grover, V. Research note: Investigating two contradictory views of formative measurement in information systems research. Mis Q. 2010, 2010, 345-365. [CrossRef]

107. Diamantopoulos, A.; Siguaw, J.A. Formative versus reflective indicators in organizational measure development: A comparison and empirical illustration. Br. J. Manag. 2006, 17, 263-282. [CrossRef]

108. Helm, S.; Eggert, A.; Garnefeld, I. Modeling the impact of corporate reputation on customer satisfaction and loyalty using partial least squares. In Handbook of Partial Least Squares; Springer: Berlin/Heidelberg, Germany, 2010; pp. 515-534.

109. Chin, W.W. The partial least squares approach to structural equation modeling. Mod. Methods Bus. Res. 1998, 295, 295-336.

110. Mondejar, J.J.; Mondejar, J.J.; Vargas, V.M.; Gazquez, A.J. Personal attitudes in environmental protection. Int. J. Environ. Res. 2012, 6, 1039-1044.

(C) 2020 by the authors. Licensee MDPI, Basel, Switzerland. This article is an open access article distributed under the terms and conditions of the Creative Commons Attribution (CC BY) license (http://creativecommons.org/licenses/by/4.0/). 